\title{
Raízes antropofágicas: labirintos e paradoxos na constituição formativa do modernismo brasileiro. ${ }^{1}$
}

\section{Fenômenos Antropofágicos: reflexos e paradoxos da percepção fenomenológica de Merleau-Ponty na leitura visual do corpo na pós-modernidade ${ }^{2}$}

Marta Lucia Pereira Martins Lindote ${ }^{3}$, Francine Regis Goudel ${ }^{4}$, Muriel Bombana Garcez 5 .

\section{Resumo}

O enfoque do artigo é dado principalmente aos Fenômenos Antropofágicos, relacionando concomitantemente a fenomenologia da antropofagia ritual Tupinambá do Brasil Colônia à Fenomenologia da Percepção de Merleau-Ponty, cuja pesquisa consiste em investigar a percepção fenomenológica da Antropofagia na Arte, no intuito de explorar a leitura visual do corpo na pós-modernidade sob o foco de uma leitura ao mesmo tempo fenomenológica e antropofágica, incluindo reflexões que abordam desde a Antropofagia oriunda do Ritual Antropofágico Tupinambá, ao presente contexto da arte no país e no mundo.

\section{Palavras-chave:}

Corpo, Fenômenos Antropofágicos, Fenomenologia da Percepção, Arte pós-moderna.

O corpo, a carnalidade e a carga sensível da obra de arte são problemáticas constantes na atualidade, amplamente discutidas nos diálogos dos teóricos que permeiam o âmbito das artes visuais na pós-modernidade.

\footnotetext{
${ }^{1}$ Projeto de Pesquisa DAP / CEART / UDESC.

${ }^{2}$ Artigo de Pesquisa produzido por Muriel Bombana Garcez.

${ }^{3}$ Orientadora, Professora do Departamento de Artes Plásticas - Centro de Artes da Universidade do Estado de Santa Catarina - UDESC - Av. Madre Benvenutta, 1907. Itacorubi - CEP 88.035-001 Florianópolis - SC.

${ }^{4}$ Acadêmica do curso de Artes Plásticas com habilitação em Licenciatura - DAP / UDESC, bolsista de iniciação científica do PROBIC / CNPq.

${ }^{5}$ Acadêmica do curso de Artes Plásticas com habilitação em Bacharelado - DAP / UDESC, bolsista de iniciação científica do PROBIC / CNPq.
} 
A obra de arte pós-moderna, não raro, abrange questões que discutem o caráter ilusionístico da imagem, questões que vão além da mera representação da imagem, questões que tratam tanto da transitividade dos corpos, quanto da transcendência da imagem.

As idéias de transitividade dos corpos e de transcendência da imagem resplandecem na obra de arte pós-moderna principalmente pelo caráter fotográfico e ilusionístico da imagem, constantemente presente no processo das obras de arte na atualidade.

A obra de arte pós-moderna é frequentemente composta por imagens de um corpo submetido a recortes fotográficos, detalhes de imagens constituídos por fragmentos de um corpo que focam composições específicas, pensadas e criadas pelo olhar e enfoque do propositor, com objetivo de aguçar as sensibilidades e percepções do espectador por meio de intrigantes imagens reproduzidas a partir e através do corpo.

Buscando explorar o corpo como objeto artístico, ser pictórico, passível de ser reinventado e resignificado pela arte, a obra de arte pós-moderna que visa exprimir a corporeidade, a carnalidade e a carga sensível tanto do corpo quanto da arte, expressa não só a plasticidade figurativa e ou corpórea do corpo, mas algo para além, capaz de transcender os conceitos até então despertados pela representação.

“[...] Hoje, é difícil ser um artista da imagem, na medida em que a máquina de representação, no seu sentido de imitação, é bastante obsoleta e que o conceito de representação deve ser ampliado por outros conceitos, como, por exemplo, o de Apresentação."

“[...] De fato, representar implicou sempre não apenas em re-produzir, mas, se tratava mesmo de reproduzir, acepção mais banal e pobre do representar imitativo, era preciso distância para poder enxergar como o real manifestaria sua representatividade ou sua apresentabilidade. A Representação sempre trabalhou por manifestar o real pela diferença. Nesse sentido, poderíamos dizer que a diferença representacional é um modo de surgimento da aparência, isto é, do perfil das coisas e dos fenômenos."

"Nisso tudo, a imagem é concebida como um fator 'realizante', 'realófilo', uma potência da realidade. Em termos fenomenológicos, realizar a realidade pela imagem não é nada menos que a "profilar", manifestá-la e constituir seu sentido, e não somente reproduzi-la como sua sombra desqualificada. Edmund Husserl, fundador da Fenomenologia, insistiu muito em dizer que conhecemos os fenômenos por perfis ('Abschattungen'), porque não há abarcamento total da realidade que seja possível. O artista faz do perfil seu possível. [...]”.

(HUCET. 2001.p. 05) 
A arte pós-moderna já não tem nada a ver com representação, em vez de refletir a vida através da representatividade, a arte pós-moderna se soma à seus conteúdos, se apropriando das imagens, formas, corpos e conteúdos ao se inserir no mundo. Desse modo as imagens não mais representam, mas simulam, pois a arte cria não exatamente as imagens, mas também seus significados.

Assim, arte e realidade, funcionam na atualidade, nas mesmas condições, como criadoras de significado e portadoras de significado, permitindo convites à interpretação e reinterpretação. As imagens e ou as obras artísticas:

“[...] prontas para absorver sentidos e significados, enfrentam o espectador contemporâneo como fantasmas: intrigantes e intensas, embaraçosas e sedutoras pelo que elas próprias são [...] graças a seus criadores e a seus receptores inclinados à interpretação. [...]”.

“O autor de imagens (e ou obras) pós-modernas é um animador ou apresentador, mais do que criador. [...] A autoria consiste no ato de montar o processo em movimento, enquanto o processo [...] funciona [...] de maneira livre e desabrida, através de muitos caminhos - e continua incompleto e aberto..."

(JAMROZIAK, Ana. In: BAUMAN. 1998. p. 135)

O significado da arte pós-moderna, pode-se dizer conforme Bauman, é estimular o processo de elaboração do significado, alertar para a inerente polifonia do significado e para a complexidade de toda interpretação; prever a solidificação de qualquer invenção que detenha o fluxo de possibilidades. A arte pós-moderna traz para o espaço aberto o perene inacabamento dos significados, acentuando a liberdade por manter a imaginação desperta, e assim manter as possibilidades vivas.

“[...] A expressão daquilo que existe é uma tarefa infinita."

$\mathrm{O}$ artista “[...] retoma e converte justamente em objeto visível o que sem ele permanece encerrado na vida separada de cada consciência [...].”

O artista deve “[...] não apenas criar e exprimir uma idéia, mas ainda despertar as experiências que a enraizarão nas outras consciências. [...]"

“[...] O artista é aquele que fixa e torna acessível aos mais 'humanos’ dos homens o espetáculo de que fazem parte sem vê-lo. [...]"

O artista é aquele que busca re(a)presentar “[...] o mundo, convertê-lo inteiramente em espetáculo, fazer ver como ele nos toca. [...]"

(MERLEAU-PONTY. 2004. p. 131- 135)

DAPesquisa, Florianópolis, v.3 n.5, p.308-315, 2008. 
Ver é tocar, tocar é ver. Segundo Merleau-Ponty:

“[...] todo visível é moldado no sensível, todo ser táctil está voltado de alguma maneira à visibilidade, havendo, assim, imbricação e cruzamento, não apenas entre o que é tocado e quem toca, mas também entre o tangível e o visível que está nele incrustado [...].

Estamos afastados das coisas "por toda a espessura do olhar e do corpo [...] que é a espessura da carne entre o vidente e a coisa". Esta espessura "não é um obstáculo entre ambos, mas o meio de se comunicarem" Assim, "em vez de rivalizar com a espessura do mundo, a de meu corpo é, ao contrário, o único meio que possuo para chegar ao âmago das coisas, fazendo-me mundo e fazendo-as carne" Pois "meu corpo é concomitantemente, corpo fenomenal e corpo objetivo", considerando que “[...] o corpo [...] reúne [...] sua dupla pertencença à ordem do 'objeto' e à ordem do ‘sujeito' [...] sendo, ele próprio, visível e tangível". "O corpo pertence à ordem das coisas, e assim como o mundo é a carne universal."

“O corpo interposto não é propriamente coisa, matéria intersticial, tecido conjuntivo, mas sensível em si, [...] sensível exemplar, que capacita a quem o habita e o sente de sentir tudo o que de fora se assemelha".

No momento em que o corpo "se deixa captar por um de seus fragmentos, o principio da captação está assimilado, e o campo aberto para [...] uma "intercorporeidade" onde o corpo "incorpora todo o sensível e, graças ao mesmo movimento, incorpora-se a si mesmo num 'Sensível em si"”, e nesse instante "há recíproca inserção e entrelaçamento de um no outro", "há, enfim, propagação dessas trocas para todos os corpos [...] que lateralmente, faz os órgãos de meu corpo entrarem em comunicação, fundando a transitividade de um corpo a outro." (MERLEAU-PONTY. 1999. p.130 - 139)

Nesse sentido, pode-se dizer que a transitividade de um corpo a outro dá-se a partir e através do corpo, por meio da fenomenologia da percepção, que consiste na idéia da percepção do outro por meio do entrelaçamento com o outro, por meio da compreensão e apreensão do outro, como um visualizar, tatear, sentir e identificar o outro para assimilar suas qualidades. Qualidades que vão além da constituição imagética do outro, que transcendem o mistério figural do visível e do tangível, qualidades que possuem autonomia, corporalidade, carnalidade, carga sensível, qualidades camufladas, instigantes, intrigantes, enigmáticas, capazes de ativar as sensibilidades e assim tornar possíveis as percepções a partir e através do corpo. 
Neste contexto, onde as percepções e sensibilidades tornam-se possíveis a partir e através do corpo, pode-se pensar a leitura visual do corpo na pós-modernidade não só sob a perspectiva da Fenomenologia da Percepção de Merleau-Ponty, mas também sob a perspectiva dos Fenômenos Antropofágicos oriundos do Ritual Antropofágico Tupinambá, pois trata-se aqui, de se pensar a problemática da percepção sob o ponto de vista de uma percepção especifica, capaz de identificar e caracterizar uma percepção ao mesmo tempo fenomenológica e antropofágica do corpo na atualidade, de modo a sugerir que a questão do corpo na arte pode ser pensada também a partir de uma relação concomitante entre a Fenomenologia e a Antropofagia, se interpretada sob o foco onde a transitividade de um corpo a outro, torna-se possível por meio da percepção e assimilação do outro, onde o devorar o outro, o apropriar-se do outro, pode ser interpretado não só como um apoderar-se da alma, da vitalidade e da corporalidade do outro, e sim como um apropriar-se de toda a constituição imagética do outro.

Sob este foco, pode-se considerar que os fenômenos antropofágicos consistem na idéia de apropriação do outro; como um devorar o outro para assimilar suas potencialidades, do mesmo modo que os fenômenos da percepção consistem na idéia de apreensão do outro, como um reconhecer o outro para perceber suas qualidades. E dada a constatação de que a percepção fenomenológica é a especificidade do homem, pode-se considerar com isso que a fenomenologia da percepção refere-se a percepção especificamente a partir e através do corpo, do mesmo modo que a fenomenologia antropofágica refere-se a assimilação especificamente a partir e através do corpo.

Compreender-se, portanto, que tanto a fenomenologia da percepção quanto a fenomenologia da antropofagia, acabam por fim, por convergir à um mesmo conceito, onde ambas referem-se ao corpo como um corpo "sensível em si, sensível exemplar", referem-se ao corpo como um corpo que sente, corpo que pensa, capaz de perceber e assimilar o que de fora se assemelha. Com isso, pode-se relacionar a idéia de corpo embutida no conceito da fenomenologia da percepção à idéia de corpo embutida no conceito da fenomenologia da antropofagia, de modo que no ritual antropofágico o corpo interposto também não é propriamente, ou somente, corpo, coisa, matéria, e nem mesmo é apenas carne, ou alimento para abastar a fome, mas é "sensível em si, sensível exemplar", tal qual na fenomenologia da percepção, é meio transcendental, que possibilita e torna ciente todas as sensações, percepções e assimilações provenientes do outro.

Se por um lado, o processo de assimilação do outro na fenomenologia da percepção, ocorre por meio da compreensão e apreensão do outro, como um visualizar, tatear, sentir e 
identificar o outro para assimilar suas qualidades. Por outro lado, o processo de assimilação do outro, na fenomenologia da antropofagia, ocorre por meio da devoração do corpo do outro, como um "engolir" ou "digerir" o outro para assimilar suas potencialidades. "[...] Antropofagia. Absorção do inimigo sacro. Para transformá-lo em totem.” (ANDRADE, 1928)

Pode-se dizer que, em ambos os casos, o princípio conceitual fenomenológico do processo de assimilação do outro é o mesmo, de modo que tanto na fenomenologia da percepção quanto na fenomenologia da antropofagia, no momento em que o corpo é percebido e ou assimilado, esse processo dá-se a princípio por um de seus fragmentos, e a partir de então, abre-se o campo da percepção e da assimilação para a transitividade dos corpos, gerando assim uma intercorporeidade, onde o corpo incorpora e ou encarna toda a corporalidade, toda a carnalidade e toda a carga sensível do outro, e nesse instante "há recíproca inserção e entrelaçamento de um no outro", "há, enfim, propagação dessas trocas para todos os corpos" sensíveis de meu próprio corpo, de modo que meu corpo agora sensibilizado, torna possível a “transitividade de um corpo a outro". (MERLEAU-PONTY, p.139)

“[...] Doravante meu corpo pode comportar segmentos tomados do corpo dos outros assim como minha substância passa para eles [...]"

(MERLEAU-PONTY. 2004. p.23)

“[...] A coisa e o mundo me são dados com as partes de meu corpo [...] em uma conexão viva comparável, ou antes idêntica à que existe entre as partes de meu próprio corpo."

“A percepção exterior e a percepção do próprio corpo variam conjuntamente porque elas são as duas faces de um mesmo ato. [...]"

(MERLEAU-PONTY. 1999. p. 276)

Partindo dessa premissa, pode-se ainda relacionar os fenômenos perceptivos aos fenômenos antropofágicos ao considerar que o princípio fenomenológico que sustenta tanto a fenomenologia da percepção quanto a fenomenologia da antropofagia "se manifesta tanto através de sua existência quase carnal da idéia, quanto por uma sublimação da carne." (MERLEAU-PONTY p.149)

Com base na relação pré-estabelecida entre Fenômenos Antropofágicos e Fenômenos da Percepção, pode-se agora pensar a questão do corpo na arte, sob a perspectiva de um entrelaçamento entre corpo e obra presente na leitura visual do corpo na pós-modernidade. 
Corpo e obra entrelaçados, agora unificados como corpo-obra, ser pictórico, objeto artístico, objeto pensante, espaço de inquietação e resignificação de idéias.

Corpo-obra, corpo que passa a ser a própria obra, que passa a ser a própria arte, que passa a ser seu próprio discurso. Corpo que ganha autonomia, carnalidade, carga sensível, subjetividade. Corpo que pode mais do que ser representado, que pode ser reinventado, resignificado. Corpo que pode apropriar-se ou ser apropriado pela obra e pela arte. Corpo que pode tocar e ser tocado, que pode ver e ser visto, que pode sensibilizar e ser sensibilizado.

Corpo que sente, corpo que pensa, corpo que punge, corpo que lampeja, corpo que tem vida própria. Corpo que simula, corpo que alegoriza, corpo que re(a)presenta, corpo que resplandece, corpo que transcende o próprio corpo.

É à esse corpo que o contexto da arte pós-moderna se refere, é à esse corpo que a fenomenologia da percepção e a fenomenologia da antropofagia se referem. Se referem à um corpo ambíguo, múltiplo, multifacetado, fragmentado, tramado, entrelaçado, recombinado, reconstituído, reinventado, resignificado, re(a)presentado. Se referem à um corpo que se utiliza da semelhança, que se utiliza da derivação de um corpo matriz. Se referem à um corpo que não cabe em si, que anseia por vida própria. Se referem à um corpo que busca se expandir continuamente. Se referem à um corpo que se utiliza da similitude, que se utiliza do simulacro do próprio corpo. Se referem à um corpo que encontra na arte, artifício para cintilar incessantemente. Se referem à um corpo que não se satisfaz apenas por se assemelhar a um corpo. Se referem à um corpo que precisa similar em si infinitamente.

"Havia lá um futuro: escorrem ainda pelos muros do labirinto, e entre raízes, as babas do cauim.” (MARTINS, 2006) 


\section{Referências Bibliográficas:}

ANDRADE, Oswald. Manifesto Antropófago. In: Revista de Antropofagia, Ano 1, $\quad \mathrm{N}^{0} 1$, São Paulo, maio de 1928.

BAUMAN, Zygmunt. O significado da Arte, a Arte do significado. In: O mal-estar da PósModernidade. RJ. Jorge Zahar Editor. 1998.

HUCET, Stéphane. Linhas de Fuga. CEMIG. BH/MG. 2001

MARTINS, Marta. Babas no muro do labirinto. Texto apresentado no Colóquio Pós-crítica, na Universidade Federal de Santa Catarina, Florianópolis, Dez/2006.

MERLEAU-PONTY. Maurice. A dúvida de Cézanne. Publicado originalmente em Fontaine. 1945. pp. 80-100. In: O olho e o espírito. SP. Cosac \& Naify. 2004.

MERLEAU-PONTY. Maurice. Fenomenologia da Percepção. SP. Martins Fontes. 1999. MERLEAU-PONTY. Maurice. O entrelaçamento - o quiasma. In: O visível e o Invisível. SP. Editora Perspectiva.1999.

MERLEAU-PONTY. Maurice. O olho e o espírito. Publicado originalmente em Art de France, n. 1, 1961. In: O olho e o espírito. SP. Cosac \& Naify. 2004. 